\title{
Technical Communication: Partner in ABET Accreditation and Assessment
}

\author{
Marjorie T. Davis \\ Mercer University
}

Introduction

EC 2000 has caused major revisions in engineering schools all over the country. Engineering educators have had to redefine the ways they are assessing all the facets of engineering education, including selecting specific deliverables to demonstrate student achievement in each of the educational outcomes. This shift to outcomes-based assessment rather than bean-counting has inflicted heartburn on hundreds of engineering professors around the country; the ones who are not experiencing the pain simply have not yet begun to deal with EC 2000 in a substantive way.

Lost in all this shuffle is Criterion 3-g, requiring that students demonstrate effectiveness in communication. Most engineering professors will want to address communication last, after they have dealt with the criteria relating to the "hard-core" engineering subjects. Many of them may be assuming that they can just leave all this assessment to their local English teachers. The problem with this assumption, however, is that English teachers are not typically ready to engage in the kinds of assessment that will be most appropriate for achieving EC 2000 goals. There will not be conceptual agreement on what is to be assessed, or why, or how. Astute EC2000 evaluators will be able to recognize the great gulf between what the criteria hope to achieve and what engineering educators may be leaving to chance.

Herein lies the problem. Ideally those who are responsible for instruction in communication will be ready, able, and willing to assess it for EC 2000; but many English teachers have no awareness of ABET's criteria and little understanding of the kinds of communication expected in the professional engineer's working environments. Therefore, engineering educators need to look for technical communication faculty to assist with communication assessment that matches the engineering contexts.

\section{Background}

Since engineering first began to emerge as a profession, engineering educators have called on fellow academics in English for help in assuring the communication competency of their graduates. As Teresa Kynell points out, the earliest impetus for academic courses in technical communication came from the professional organization that was the forerunner to ASEE. ${ }^{1}$ Kynell traces the conference presentations over a hundred years starting in 1850, showing how engineering professors continually asked for more and different kinds of instruction than the traditional classroom-focused, essay-based writing. They wanted writing and speaking instruction that directly related to the kinds of real-world tasks engineers were expected to perform as the profession struggled for its status.

The situation is not so very different today. Employers and educators of engineers need and want young professionals to be able to perform in complex communication tasks. They must communicate with many different kinds of audiences, in many formats (both oral and written), for a variety of purposes. Most of these tasks are not closely related at all to what is traditionally taught in Freshman English or speech classes. The real-world context is still missing, and the audience remains primarily the teacher. It is not at 
all surprising that the gulf exists between engineering and English departments. There are very different missions for the two disciplines: English educates people to be, and Engineering educates people to do. These differing missions help explain the difficulties engineering educators will have in relying on most English professors to be solely responsible for assessing engineering communication for EC 2000.

\section{More Compatible Partners}

Technical communication educators are likely to be more compatible partners with engineering than English teachers are. Like engineers, they take principles or theories and apply them to real-world problems. They are able, and willing, to cross the disciplinary divides to work side by side with engineers. They are focused on professional practice and well as on theory, and their deliverables more closely match the demonstration of educational objectives for EC 2000.

In EC 2000, technical communication is emphasized more than ever. It will not be enough for faculty to point to English courses and claim that students have mastered communication in engineering contexts. Indeed, we will have to demonstrate that students have mastered higher level communication tasks such as these:

- Communicating technical information for decision-makers in corporate contexts

- Explaining technically complex, emotionally charged information for public uses and citizens' decisions

- Communicating persuasively in competitive environments (such as bids, proposals)

- Creating effective user interfaces for engineering products

- Demonstrating competence in engineering design and analysis through effective documents, graphics, and presentations

- Managing interpersonal communication in sometimes stressful team projects

- Communicating effectively with management to demonstrate expertise and achievements

- Communicating with implementers and users of engineering products (such as technicians or the public)

- Conveying concepts of risks, including probability of failures (think of Challenger, for example)

- Understanding liability related to communication documents

A quick review of this list alone (and it is not to be considered completed) can demonstrate how far our engineering students have yet to go, if we rely only upon essay writing and basic speech courses for their instruction.

\section{The Benefits of New Partnerships}

To succeed in this effort, we must form partnerships between engineering and technical communication faculty. Even if schools of engineering do not have departments of technical communication themselves, they will be able to find individuals who may have the breadth and depth of knowledge and teaching of technical communication to assist them. This partnership will be beneficial to engineering professors for the obvious assessment reasons; however, the technical communication professors will also gain a great deal from this relationship. Given the backing and support from engineering, they may be able to extend their expertise in the fields of outcomes assessment and technical communication; to secure support for research or consulting time in engineering and corporate contexts for hands-on experiences; to design new courses offered within the school of engineering to meet EC 2000 and local program goals; and to generate new research and publications that will help them professionally. The ones who will benefit most from this partnership, however, are the students. They will leave our universities with the depth of communication expertise that will help to assure that they are effective, productive engineers who will be assets to their companies and to their communities. 
These are the keys to a partnership between engineering educators and technical communication educators:

1) Extending ABET Awareness-Engineering educators must take the initiative to educate their technical communication colleagues about ABET and EC 2000. Accustomed to a liberal arts environment as most of them are, they will need help in understanding what professional accreditation means and how ABET works. Engineers will need to do some excellent communication of their own by carefully analyzing their audience's knowledge, skills, values, and commonly held assumptions. Approaching any audience on common ground is the key to most successful communications.

2) Defining Assessment Standards-Technical communicators and engineers must together work towards defining the standards, measures, and deliverables for demonstrating communication competency. A number of technical communication faculty have solid expertise in writing assessment (focusing primarily upon the essay); while this knowledge is not enough, it is a good start towards reaching farther into engineering-related practice for communication tasks and evaluations. Engineers have a good grasp of creating and testing alternatives and assumptions, as well as analyzing data. Together, they will be able to create good assessment plans and implement them. Setting the standards will be one of the most difficult issues. These standards must be rooted in industry best practices, rather than in theory or academic settings alone.

3) Fostering Faculty Development-Engineering deans should sponsor technical communicators to attend an ABET training session; additionally, they should encourage technical communication faculty to join such organizations as ASEE and IEEE Professional Communication Society. Likewise engineering educators must make it their business to learn about technical communication and assume responsibility for it themselves. Not many current professors had formal instruction in technical communication-it has been acquired over the years by trial and error. Engineers can benefit from recent research, theory, and practice of excellent technical communication techniques, just as technical communicators can benefit from exposure to the engineering world.

4) Reaching Broader Assessment Goals-Technical communicators can be valuable partners in helping to assess all of the "softer skills" in EC 2000, such as these:

(d) an ability to function on multi-disciplinary teams - teaching group/team communication strategies in classes; assessing the group processes involved in a team engineering project such as a senior design; or using personality inventories to learn to handle style conflicts

(f) an understanding of professional and ethical responsibility-including perhaps some of the excellent case studies now available on the web on engineering ethics, the codes of the different professional societies (such as NSPE, IEEE, and others)

$(\mathrm{g})$ an ability to communicate effectively — defining "effectively" specifically for that institution's mission and goals, but always focused on engineering practice in addition to basic academic competency

(h) the broad education necessary to understand the impact of engineering solutions in a global and societal context - issues of communicating with international audiences create appropriate opportunities to discuss graphics, language use, document formatting, cultural values; studying unintended consequences of engineering innovations can broaden awareness of engineering's impact on society and the environment

(i) a recognition of the need for, and an ability to engage in life-long learning - teaching engineers to become self-sufficient searchers for knowledge in many different contexts, including web-based research, informational interviews, etc.; using software upgrades as a subject for self-instruction and critiquing usability of engineered products

(j) a knowledge of contemporary issues - overcoming the natural isolation of college students with attention to developing events such as the shifting of software hiring to Indian programmers (subject of a recent NPR interview); bringing controversial topics into discussion among a mixed group of engineering, business, and liberal arts majors; 
creating a web page with current events related to engineering or technology; and so forth.

These are only a few examples to illustrate how technical communication faculty can enrich educational experiences for engineering students by introducing some nontraditional topics and assignments into various classes in engineering and technical communication.

\section{Conclusion}

Using their knowledge and skills in writing, in presenting information orally, in designing documents appropriate to audience and purpose, in communicating within organizations, etc., technical communicators can be valuable partners with engineering educators in meeting the expectations of ABET's EC 2000. This partnership will enhance not only our efforts to achieve success in reaching ABET's goals, but it will pay important dividends to our faculty, our students, and their future employers.

Bibliography

1. Kynell, Teresa C. Writing in a Milieu of Utility: The Move to Technical Communication in American Engineering Programs 1850-1950. Norwood, NJ: Ablex, 1996.

\section{MARJORIE T. DAVIS}

Marjorie T. Davis is a Professor in the School of Engineering at Mercer University, Macon, Georgia. She is founding chair of the Department of Technical Communication, which offers both BS and MS degrees in technical communication. She chairs the Assessment Committee and serves as Course Coordinator for one of the required freshman engineering core courses. She is a senior member of IEEE and serves on the Professional Communication Society AdCom. She is also a member of ASEE, Society for Technical Communication, Council for Programs in Technical \& Scientific Communication, and ATTW. 